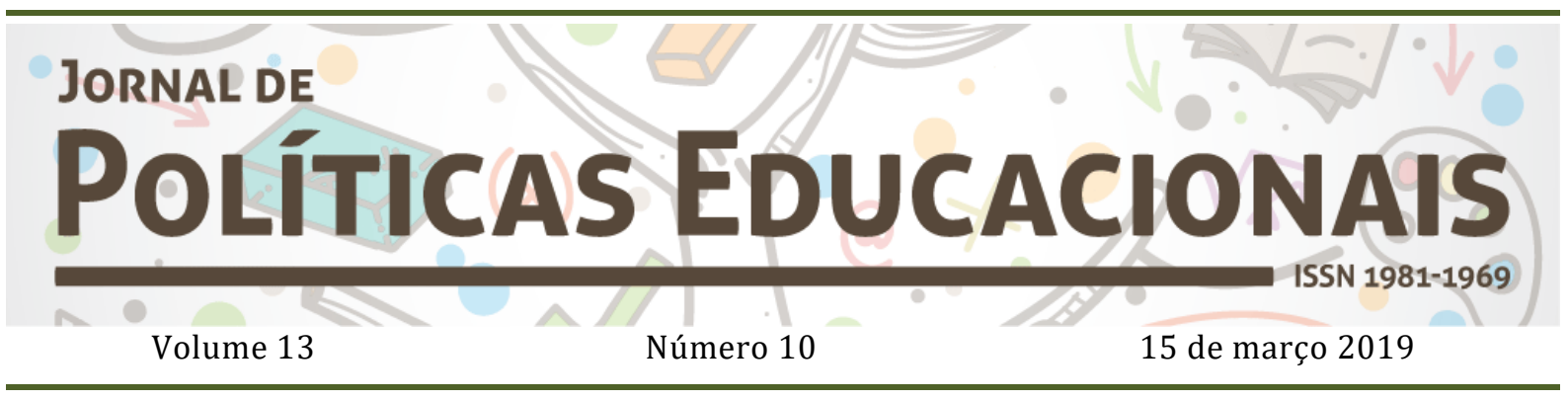

\title{
0 princípio de autonomia dos institutos federais e sua política educacional em oposição à reforma do ensino médio
}

\section{The principle of autonomy of the federal institutes and its educational policy in opposition to the reform of high school}

\section{El principio de autonomía de los institutos federales y su política educativa en oposición a la reforma de la enseñanza media}

\author{
Marcelo Velloso Heeren ${ }^{1}$ \\ Marta Leandro Da Silva ${ }^{2}$
}

Citação: HEEREN, M. V.; SILVA, M. L. da. O princípio de autonomia dos institutos federais e sua política educacional em oposição à reforma do ensino médio. Jornal de Políticas Educacionais. V. 13, n. 10. Março de 2019.

\section{Resumo}

O objetivo da presente pesquisa foi analisar a Lei 13.415/17, que regulamenta a reforma do ensino médio, caracterizando os aspectos conflitantes em relação ao princípio de autonomia e da produção dos atos normativos específicos dos institutos federais (IFs). A pesquisa segue abordagem de pesquisa qualitativa em educação com destaque para a pesquisa e análise documental. Os institutos federais possuem uma autonomia relativa condizente à sua natureza jurídica de "autarquia federal". Essa condição legal determina que as ações políticas, pedagógicas, didáticas e estruturais dos IFs devem ser guiadas para a obtenção dos objetivos e finalidades para a qual a instituição foi criada. A Lei 11.892/08 que instituiu a criação da Rede Federal de Educação define suas finalidades e apresenta o Ensino Profissional Técnico de Nível Médio (EPTNM) na modalidade integrada como prioridade de oferta dos IFs. A Resolução CEB/CNE n.o 6/12 indica a formação integral do estudante como finalidade do EPTNM, objetivo contrário à formação fragmentada indicada pela reforma. Ainda é relevante ressaltar que as modificações no texto da LDB não fazem referência à EPTNM, fato este que também convalida a manutenção do modelo de ensino médio adotado pelos IFs. Existem indicações jurídico-normativas que possibilitam aos IFs a manutenção da sua política curricular, convalidando assim o relativo grau de autonomia e as prerrogativas dos IFs diante da sua atuação político-pedagógica necessária para a consolidação das suas finalidades institucionais.

\footnotetext{
${ }^{1}$ Doutorando do programa de pós-graduação em Educação Escolar da Unesp, Campus Araraquara. Professor do Instituto Federal de Educação, Ciência e Tecnologia de São Paulo, Catanduva. marceloheeren@gmail.com ${ }^{2}$ Docente do programa de pós-graduação em Educação Escolar da Unesp, Campus Araraquara. martaleandro@fclar.unesp.br
} 
HEEREN, M. V.; SILVA, M. L. da. O princípio de autonomia dos institutos federais e sua política educacional em oposição à reforma do ensino médio.

Palavras-chave: Instituto Federal, Reforma Educacional, Ensino Médio, Política Educacional

\begin{abstract}
The objective of this research was to analyze the Brazilian Law 13.415/17, which regulates the reform of high school, characterizing the conflicting aspects in relation to the principle of autonomy and the production of specific normative acts of the Federal Institutes (FIs). The research follows qualitative research approach in education emphasizing research/and documentary analysis. The federal institutes possess a relative autonomy in keeping their legal nature as "Federal Autarchy". This legal condition determines that the political, pedagogical, didactic and structural actions of FIs should be guided to the achievement of the objectives and purposes for which the institution was created. The Law 11.892/08, which instituted the creation of the Federal Education Network, defined its purposes and presents the Secondary Technical Education (EPTNM) in the integrated modality as a priority of the FIs' offer. The Resolution CEB/CNE number 6/12 indicates the integral formation of the student as a purpose of the EPTNM, an objective contrary to the fragmented formation indicated by the reform. It is still relevant to note that the modifications in the text of the LDB do not reference the FIs. There are juridical-normative indications that allow FIs to maintain their curricular policy, thus validating the relative degree of autonomy and the prerogatives FIs in face of their political-pedagogical action necessary for the consolidation of their institutional purposes.
\end{abstract}

Keywords: Federal Institute, Educational Reform, Secondary Education, Educational Policy

\title{
Resumen
}

El objetivo de la presente investigación fue analizar la ley brasileña 13.415/17, que regula la reforma de la enseñanza media, caracterizando los aspectos conflictivos en relación al principio de autonomía y de la producción de los actos normativos específicos de los Institutos Federales (IFs). La investigación sigue el enfoque de investigación cualitativa en educación con destaque para la investigación y el análisis documental. Los Institutos federales poseen una autonomía relativa acorde a su naturaleza jurídica de "Autarquía Federal". Esta condición legal determina que las acciones políticas, pedagógicas, didácticas y estructurales de los IFs deben ser guiadas para la obtención de los objetivos y finalidades para la cual la institución fue creada. La ley 11.892/08 que instituyó la creación de la Red Federal de Educación definió sus finalidades y presenta la Enseñanza Profesional Técnico de Nivel medio (EPTNM) en la modalidad integrada como prioridad de oferta de los IFs. La resolución CEB/CNE $n^{\circ}$ 6/12 indica la formación integral del estudiante como finalidad del EPTNM, objetivo contrario a la formación fragmentada indicada por la reforma. Es importante resaltar que las modificaciones en el texto de la LDB no hacen referencia a la EPTNM, hecho que también convalida el mantenimiento del modelo de enseñanza media adoptado por los IFs. Existen indicaciones jurídico-normativas que posibilitan a los IFs el mantenimiento de su política curricular, convalidando así el relativo grado de autonomía y las prerrogativas de los IFs ante su actuación política-pedagógica necesaria para la consolidación de sus finalidades institucionales.

Palabras clave: Instituto Federal, Reforma Educativa, Enseñanza Media, Política Educativa

\section{Introdução}

Este artigo reporta-se às atividades relacionadas ao projeto de pesquisa de doutorado em Educação e às atividades do grupo de pesquisa, sob enfoque de pesquisa qualitativa, versando sobre a reforma do ensino médio aprovada em 2017 no contexto das políticas públicas educacionais a partir da Constituição Federal de 1988 e especificações advindas da Lei de Diretrizes e Bases da Educação (LDB) n.o 9394/96; articula-se ainda aos estudos concernentes ao papel do poder legislativo na formulação, execução, acompanhamento e avaliação de políticas públicas educacionais. 
Neste espaço textual objetivou-se a análise dos aspectos qualitativos do texto da Lei 13.415/17, que regulamenta a reforma do ensino médio e a contradição existente para a sua implementação no âmbito da Rede Federal de Ensino dos institutos federais de educação, ciência e tecnologia. 0 artigo apresenta uma análise da referida lei, caracterizando os aspectos conflitantes em relação ao princípio de autonomia e da produção dos atos normativos específicos dos institutos federais.

A pesquisa segue abordagem de pesquisa qualitativa em educação com destaque para a pesquisa e análise documental articulada da revisão bibliográfica e ao referencial teórico-metodológico de perspectiva interdisciplinar na interface ciências políticas e ciências jurídicas (direito à educação) e, especificamente, na área de gestão e política educacional.

\section{o princípio de autonomia dos institutos federais: revisitando o conceito de autarquia}

A autonomia das instituições de ensino, no Brasil, configura-se como temática muito relevante e não recente, constituindo-se em um campo de discussão e reflexão necessário a considerar a efetividade dos princípios estabelecidos na atual LDB, notoriamente, quanto à gestão democrática do ensino público; igualdade, liberdade e pluralismo de ideias e de concepções pedagógicas (BRASIL, 1996). É importante destacar alguns apontamentos referentes à especificidade do termo "autonomia" articulado e parametrizado no contexto de diferentes instituições públicas de ensino. Neste momento, objetiva-se abordar o princípio de autonomia no âmbito dos institutos federais de educação, ciência e tecnologia, com foco de análise no conceito de "autonomia" e sua correlação quanto à natureza jurídica autárquica federal inerente às entidades pertencentes à Rede Federal de Educação Profissional e Tecnológica.

Nos termos da legislação federal, o conceito de autarquia está disposto no artigo

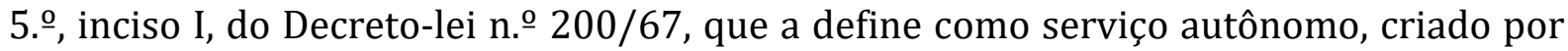
lei, com personalidade jurídica, patrimônio e receita própria, para executar atividades típicas da administração pública, que requeiram, para seu melhor funcionamento, gestão administrativa e financeira descentralizada.

A Lei n. ${ }^{0}$ 11.892/08 institui a Rede Federal de Educação Profissional e Tecnológica no Brasil, a qual compreende também os institutos federais de educação. 0 
entendimento dessa normativa se faz necessário nesta abordagem de pesquisa/análise documental, uma vez que os institutos federais apresentam natureza jurídica de autarquia federal contemplados com autonomia administrativa, patrimonial, financeira, didático-pedagógica e disciplinar inerentes às autarquias conforme artigo 1.ํㅡ,

\begin{abstract}
Art. 1o Fica instituída, no âmbito do sistema federal de ensino, a Rede Federal de Educação Profissional, Científica e Tecnológica, vinculada ao Ministério da Educação e constituída pelas seguintes instituições:

I - Institutos Federais de Educação, Ciência e Tecnologia - Institutos Federais;

II - Universidade Tecnológica Federal do Paraná - UTFPR;

III - Centros Federais de Educação Tecnológica Celso Suckow da Fonseca CEFET-RJ e de Minas Gerais - CEFET-MG;

IV - Escolas Técnicas Vinculadas às Universidades Federais.

Parágrafo único. As instituições mencionadas nos incisos I, II e III do caput deste artigo possuem natureza jurídica de autarquia, detentoras de autonomia administrativa, patrimonial, financeira, didático-pedagógica e disciplinar. (BRASIL, 2008)
\end{abstract}

As entidades autárquicas são integrantes da administração direta na estrutura do Estado. O termo autarquia correlaciona-se à faculdade/possibilidade conferida pelo próprio Estado para uma instituição/organização para fins de execução descentralizada de serviços de interesse estatal ou da coletividade, entretanto sujeitos à fiscalização da administração direta. A autarquia é uma extensão do Estado, integrando o aparelho estatal com função pública típica, ou seja, o Estado não se desfaz da sua prerrogativa de controle, ele apenas descentraliza sua gestão para atender algumas demandas específicas de maneira mais adequada.

Silva (2009), no livro intitulado Institutos Federais: Lei 11.892, de 29/12/2018, comentários e reflexões, esclarece que a autarquia administrativa é instituída por lei caracterizando essas instituições como autônomas. Entretanto não se caracterizam como "autônomas", pois devem atender à lei do poder que as criou, em observância a legislação maior no âmbito estatal, sem a possibilidade de legislar para si mesma. Dessa forma, as autarquias são entidades que, dotadas de direitos e detentoras de deveres, possuem responsabilidades na execução descentralizada das atividades típicas da administração pública. Portanto "trata-se de instituição pública-estatal dotada de determinado grau de autonomia limitada aos objetivos definidos pelo Estado através de políticas públicas vinculados a sua natureza" (SILVA, 2009, p. 18).

A partir do entendimento sobre a natureza jurídica dos institutos federais, é preciso que possamos refletir e organizar institucionalmente o conceito de autonomia presente no texto da Lei 11.892/08. 0 conceito de autonomia "pressupõe a liberdade de 
agir ou, em outras palavras, a possibilidade de autogestão, autogoverno, autonormação, ocorrendo em sistemas relacionais, em contextos de interdependência" (SILVA, 2009). Assim posto, em um contexto relacional, a autonomia se revela relativa.

\begin{abstract}
A autonomia é um conceito relacional (somos sempre autónomos de alguém ou de alguma coisa) pelo que sua ação se exerce sempre num contexto de interdependência e num sistema de relações. A autonomia é também um conceito que exprime um certo grau de relatividade: somos mais, ou menos autónomos; podemos ser autónomos em relação a umas coisas e não o ser em relação a outras. A autonomia é, por isso, uma maneira de gerir, orientar, as diversas dependências em que os indivíduos e os grupos se encontram no seu meio biológico ou social, de acordo com as suas próprias leis (BARROSO, 1996, p. 17).
\end{abstract}

Como já exposto acima, os institutos federais deverão seguir os princípios e finalidades atribuídas pela lei de criação, fazendo uso dos relativos graus de autonomia a fim de alcançar a plenitude da sua natureza institucional articulada no macro contexto das políticas públicas. Esse contexto de interdependência entre a entidade autárquica e o Estado já revela que a autonomia existente para esta entidade estatal não pode ser confundida ou reconhecida como uma soberania, mas entendida como a capacidade de autoadministração (MEIRELLES, 2016) para o atendimento dos fins institucionais já estabelecidos em legislação específica.

Partindo da disposição legal na qual revela que os institutos federais apresentam uma missão socialmente referenciada, a autonomia revela-se de forma relativa na criação, condução e implementação dos meios necessários para o alcance das finalidades estabelecidas na Lei 11.892/08, em consonância com a Lei de Diretrizes e Bases da Educação e regimentos específicos da Educação Profissional e Tecnológica. Posto isso, a análise sobre a "autonomia" dos institutos federais em relação à interpretação e cumprimento dos dispositivos legais-normativos referentes à atual reforma do ensino médio, que indica mudanças curriculares, pedagógicas e estruturais, somente se fará factível após serem observados os aspectos internos que se revelam a partir de relações políticas, administrativas e normativas próprias da Rede Federal de Educação Profissional e Tecnológica (EPT).

Primeiramente, demanda a análise e referenciação das normativas que regem a EPT e as mudanças promovidas no texto da atual LDB. Em segundo lugar, é preciso entender quais são as relações de poder existentes entre as diferentes secretarias vinculadas ao Ministério da Educação. Em terceiro lugar, apresentar possíveis 
contradições entre objetivos, princípios e finalidades da reforma do ensino médio e a política pública de educação profissional técnica de nível médio no contexto da Rede Federal. Nesse aspecto, podemos considerar, como veremos a seguir, que cabe reconhecer a relativa autonomia da Rede Federal de EPT em analisar no âmbito do seu plano de desenvolvimento institucional os interesses internos quanto ao atendimento de forma parcial e/ou integral da "política governamental de reforma do ensino médio".

\section{A organização da Secretaria de Educação Profissional e Tecnológica (Setec)}

A Secretaria de Educação Profissional e Tecnológica do Ministério da Educação (Setec/MEC) é um órgão pertencente à estrutura organizacional do Ministério da Educação e responde às normativas expedidas pelo Conselho Nacional de Educação (CNE). Figura como muito relevante, sendo, pois, responsável pela coordenação executiva da política de educação profissional e tecnológica no país. 0 fato de a EPT estar diretamente sob a égide da Secretaria de Educação Profissional e Tecnológica (Setec) revela uma singularidade importante para observarmos alguns aspectos relacionados à autonomia dos institutos federais.

De acordo com o Decreto n. 9 9.005, de 14 de março de 2017, essa secretaria tem por atribuição formular, implementar, monitorar, avaliar e induzir políticas, programas e ações de EPT, atuando em regime de colaboração com os demais sistemas de ensino e os diversos agentes sociais envolvidos na área. Nos termos do inciso 16 do artigo 15 do referido decreto, a Setec é ainda responsável pela proposição de ações com vistas à concepção e atualização de diretrizes nacionais para a oferta de cursos de educação profissional e tecnológica alinhadas às demandas sociais e aos arranjos produtivos locais. Para o desempenho das suas atribuições, a Setec conta com três diretorias: 1) Diretoria de Políticas e Regulação de Educação Profissional e Tecnológica (DPE), responsável pela formulação de políticas e pela indicação de diretrizes para organização da oferta e para avaliação da EPT, bem como pela regulação e supervisão da oferta dos cursos técnicos no âmbito do sistema federal de ensino; 2) Diretoria de Desenvolvimento da Rede Federal de Educação Profissional, Científica e Tecnológica (DDR), responsável pelo planejamento, supervisão e desenvolvimento da Rede Federal; 3) Diretoria de Articulação e Expansão de Educação Profissional e Tecnológica (DAE), responsável pela articulação entre os atores da EPT e pela implementação de programas e ações de promoção da EPT. 
Pode-se observar que a criação de uma secretaria específica que regulamenta a Educação Profissional e Tecnológica e organiza a Rede Federal de Educação Profissional e Tecnológica no país contribui para que a relativa autonomia dos institutos federais, prevista em sua prerrogativa de autarquia federal, seja concretizada em sua completude, mediando administrativa, jurídica e pedagogicamente normativas específicas para a EPT.

Além do papel de coordenadora nacional da política de EPT, a Setec/MEC responde pela criação, manutenção, supervisão e fortalecimento das instituições que compõem a Rede Federal de Educação Profissional, Científica e Tecnológica, fomentando o desenvolvimento de modelos de ensino, observadas as especificidades do público a ser atingido. Nesse contexto, o ensino profissional técnico de nível médio, considerada suas particularidades teóricas, deverá ser orientado de maneira coerente dentro da legislação específica para esse modelo educacional. Um exemplo que corrobora a descrição acima, foi a Resolução n. ํ 6, de 2012, estabelecida pela Câmara de Educação Básica do Conselho Nacional de Educação, que define as Diretrizes Curriculares Nacionais para a educação profissional técnica de nível médio, com princípios e finalidades específicos para essa modalidade de ensino.

A partir do exposto acima, podemos creditar a essa secretaria um papel fundamental na organização e coordenação dos institutos federais, observando a sua atividade reguladora inerente à sua especificidade e ainda por meio de sua representatividade político-normativa articulada ao Conselho Nacional de Educação. Nesse sentido, é evidente a necessária participação da Setec junto ao CNE na formulação ou alteração de normativas que indiquem "reformas" inerentes à ação didática, política e pedagógica dos IFs em benefício das finalidades já definidas na sua Lei de criação n.o 11.892/08.

\section{A Rede Federal de Educação Profissional, Científica e Tecnológica: organização normativa do conjunto dos institutos federais}

A Rede Federal de Educação Profissional, Científica e Tecnológica possui como documento norteador da sua atuação educacional, com definições sobre os objetivos, princípios e finalidades das instituições pertencentes, a Lei n. ${ }^{0}$ 11.892/2008, de criação da Rede Federal de Educação Profissional e Tecnológica. 0 conjunto dos institutos federais pertence a essa rede e possui uma estrutura organizacional própria que 
possibilita a sua atuação correspondente às suas finalidades e objetivos institucionais. A organização política e administrativa dos institutos federais está indicada na seção IV, "Da Estrutura Organizacional dos Institutos Federais", da referida lei, na qual estão definidos e caracterizados alguns cargos e conselhos que farão parte do organograma de todas as instituições do conjunto dos institutos federais. Pelo fato dessa instituição apresentar uma estrutura multicampi, pode-se observar a existência de uma instância central de tomada de decisão composta pelo Conselho Superior (Consup), Colégio de Dirigentes (Coldir) e a Reitoria e outra instância descentralizada de tomada de decisão composta especificamente pelos servidores de cada campus.

Os órgãos máximos da administração central dessa instituição são formados pelo Conselho Superior (Consup) e pelo Colégio de Dirigentes (Coldir). O Consup é um órgão colegiado, de caráter consultivo e deliberativo, que tem por finalidade analisar e regular as diretrizes de atuação de cada instituto federal no âmbito acadêmico e administrativo, sendo composto por "representantes dos docentes, dos estudantes, dos servidores técnico-administrativos, dos egressos da instituição, da sociedade civil, do Ministério da Educação e do Colégio de Dirigentes do Instituto Federal". Já o Coldir é um órgão de apoio ao processo decisório da Reitoria “composto pelo Reitor, pelos Pró-Reitores e pelo Diretor-Geral de cada um dos campi que integram o Instituto Federal" e possui apenas caráter consultivo. Subordinada ao Consup, a Reitoria, órgão executivo máximo da instituição, é composta pelo reitor e cinco pró-reitores, cabendo-lhe a administração, a coordenação e a supervisão de todas as atividades da autarquia.

Já a administração descentralizada da instituição compreende a estrutura de cargos e funções pertencentes a cada campus dos institutos federais, apresentando o Conselho de Câmpus (Concam) como órgão máximo normativo, consultivo e deliberativo no âmbito de cada campus, e o diretor geral, cargo executivo máximo em cada campus. Subordinado direta ou indiretamente ao diretor geral estão todas as gerências e coordenações da organização administrativa, acadêmica, pedagógica e técnica no âmbito de cada campus. É importante deixar evidente que o organograma de cada instituto federal, constando o mínimo referido na lei de criação e outras normativas educacionais, poderá apresentar uma estrutura diversa, contemplando as necessidades e especificidades da comunidade que a estabeleceu.

Toda essa estrutura de órgãos colegiados inerentes aos institutos federais compõe uma organização político-administrativa específica, com a finalidade de garantir a 
HEEREN, M. V.; SILVA, M. L. da. O princípio de autonomia dos institutos federais e sua política educacional em oposição à reforma do ensino médio.

adequação dessa instituição aos objetivos e finalidades dispostos na lei de criação dos IFs, resguardando a autonomia de cada unidade de ensino para estabelecer normativas internas condizentes com as especificidades regionais e locais de cada instituto federal.

\section{A política do ensino médio nos institutos federais}

Os institutos federais de educação caracterizam-se por serem um conjunto de instituições especializadas na oferta de educação profissional e tecnológica nas diferentes modalidades de ensino, qual seja no ensino básico, técnico ou superior. A Lei n. ${ }^{\circ} 11.892$, de 29 de dezembro de 2008, que cria os institutos federais, define como um dos objetivos da instituição, no artigo 7.ำ, priorizar a oferta da educação profissional técnica de nível médio prioritariamente na modalidade integrada:

Art. $7^{\circ}$ Observadas as finalidades e características definidas no art. 60 desta Lei, são objetivos dos Institutos Federais:

I- Ministrar educação profissional técnica de nível médio, prioritariamente na forma de cursos integrados, para os concluintes do ensino fundamental e para o público da educação de jovens e adultos; (BRASIL, 2008, p. 5).

Vale neste espaço esclarecer quanto à nomenclatura adotada no texto da Lei 11.892/08, seguida da legislação complementar, especificamente da Resolução CNE/CEB n.ำ 6, de 2012, que versa sobre as diretrizes de educação profissional técnica de nível médio, estabelece-se como nomenclatura a "educação profissional técnica de nível médio" para referir-se ao modelo de ensino médio adotado nos institutos federais.

Complementarmente, o artigo 8. ainda deixa explícito que o ensino profissional técnico de nível médio na modalidade integrada deverá compor no mínimo 50\% dos alunos matriculados na instituição.

Art. $8^{\circ}$ No desenvolvimento da sua ação acadêmica, o Instituto Federal, em cada exercício, deverá garantir o mínimo de 50\% (cinqüenta por cento) de suas vagas para atender aos objetivos definidos no inciso I do caput do art. 7o desta Lei [...] (BRASIL, 2008, p. 6).

Pode-se perceber a relevância instituída pelo Governo Federal para o desenvolvimento dessa modalidade de ensino, que apresenta uma ideia de formação ao estudante que ultrapassa os limites especificamente laboral do ensino técnico e puramente acadêmico-generalista do ensino propedêutico. A formação integral prevista nessa modalidade significa priorizar uma educação cujos objetivos são a criatividade, autonomia intelectual e formação política, não especificando capacidades, habilidades 
e/ou competências intelectuais e humanas mais importantes para o estudante, aspecto bastante reforçado quando se viabiliza a formação do aluno para as necessidades do mercado (FRIGOTTO, 2012).

Se a preparação profissional no ensino médio é uma imposição da realidade, admitir legalmente essa necessidade é um problema ético. Não obstante, se o que se persegue não é somente atender a essa necessidade, mas mudar as condições em que ela se constitui, é também uma obrigação ética e política, garantir que o ensino médio se desenvolva sobre uma base unitária para todos. Portanto, o ensino médio integrado ao ensino técnico, sob uma base unitária de formação geral, é uma condição necessária para se fazer a "travessia" para uma nova realidade. (FRIGOTTO; CIAVATTA; RAMOS, 2005a, p. 43)

Ademais, as finalidades dos institutos federais que estão expressas no artigo 6. da Lei 11.892/2008 apresentam a grande amplitude e complexidade de formação do aluno trabalhador inerente à sua ação didático-pedagógica. No texto dessa lei está indicado que o aluno deverá ter a possibilidade de formação e qualificação com vistas à atuação profissional nos diversos setores da economia, a partir de uma educação profissional e tecnológica investigativa que proporcione a geração e adaptação de soluções técnicas e tecnológicas às demandas sociais e peculiaridades regionais. Adicionalmente, também deverá fomentar o desenvolvimento de espírito crítico, voltado à investigação empírica e realizar e estimular a pesquisa aplicada, a produção cultural, o empreendedorismo, o cooperativismo e o desenvolvimento científico e tecnológico (BRASIL, 2008).

Em concordância com a Lei 11.892/08, a Resolução CNE/CEB n.ำ6/12, que define as Diretrizes Curriculares Nacionais para a educação profissional técnica de nível médio (EPTNM), indica a valorização dos aspectos humanísticos, científicos e tecnológicos do estudante como princípios norteadores da educação profissional técnica de nível médio. Ainda conforme o artigo 6.ำ da mesma resolução, os princípios da EPTNM, visando à formação integral do estudante, compreendem, entre outros, assumir o trabalho como princípio educativo e a pesquisa como princípio pedagógico, a interdisciplinaridade assegurada no currículo e na prática pedagógica visando à superação da fragmentação de conhecimentos e de segmentação da organização curricular, além de promover a articulação da educação básica com a educação profissional e tecnológica, na perspectiva da integração entre saberes específicos para a produção do conhecimento e a intervenção social.

Além desses documentos de orientação nacional, cada instituto federal poderá 
ainda criar regulamentação interna para normatizar a forma de atuação da instituição no cumprimento das disposições legais hierarquicamente superiores. Especificamente, isso se aplica no que diz respeito à possibilidade de cada instituto federal definir e implementar sua política interna de ensino, pesquisa e extensão, bem como a autonomia de cada campus em desenvolver uma matriz curricular própria dos cursos do ensino básico, técnico e superior.

\section{A lei de reforma do ensino médio: autonomia e prerrogativas dos institutos federais no processo de implementação}

A Lei 13.415/17 modificou alguns artigos da LDB referentes ao capítulo II, que orienta a educação básica, e, especificamente, a seção IV, que aborda estritamente o ensino médio propedêutico sem fazer nenhuma alteração nos artigos referentes à seção IV-A que aborda especificamente a educação profissional técnica de nível médio. Ademais, o artigo 36-B dessa seção coloca que a educação profissional técnica de nível médio deverá observar: I - os objetivos e definições contidos nas diretrizes curriculares nacionais estabelecidas pelo Conselho Nacional de Educação; II - as normas complementares dos respectivos sistemas de ensino; III - as exigências de cada instituição de ensino, nos termos do seu projeto pedagógico. Dessa forma, a Resolução CNE/CEB n. o 06/2012, que, como citado anteriormente, define as Diretrizes Curriculares Nacionais para a educação profissional técnica de nível médio, deverá nortear as normas complementares de cada instituto federal, bem como dos projetos pedagógicos de cada unidade educacional ou campus.

Nessa circunstância, a lei da reforma do ensino médio não explicita as conexões entre as diferentes modalidades/formas de organização curricular (médio integrado; concomitante e subsequente) já definidas na educação profissional e os eixos de formação criados para "o novo ensino médio". Essa diferença não prevista pela reforma do ensino médio na organização curricular traz uma contradição bastante acentuada, sobretudo em relação à perspectiva de formação integral do estudante, já mencionada anteriormente neste texto, indicada no $\S 7$ do artigo 35-A da LDB. Paradoxalmente, a reforma tal como apresentada desconsidera os pilares da formação integral, aprofundando ainda mais a exclusão social de estudantes já desfavorecidos historicamente quanto ao direito à educação de qualidade em uma perspectiva emancipadora. 
A modificação da carga horária mínima e máxima prevista para o EM indicada pela reforma, atrelada a uma nova estrutura curricular também traz inconsistências que inviabilizam a atividade educacional dos institutos federais diante dos objetivos e finalidades para as quais foram criados. No tocante aos cursos da educação profissional técnica de nível médio de cada instituto da Rede Federal e diante de um currículo unificado, a carga horária é estabelecida e definida pela Resolução n. ${ }^{\circ} 6$ CNE/CEB da seguinte forma: os cursos integrados têm as cargas horárias totais de, no mínimo, 3.000, 3.100 ou 3.200 horas, conforme o número de horas para as respectivas habilitações profissionais indicadas no Catálogo Nacional de Cursos Técnicos, seja de 800, 1.000 ou 1.200 horas.

0 artigo 1. da Lei 13.415/17 aponta que a carga horária do EM deverá ser ampliada de forma progressiva até 1.400 horas, devendo os sistemas de ensino oferecer no prazo de cinco anos pelo menos 1.000 horas anuais. Esse fato não acarreta necessariamente alguma modificação para os institutos federais (IFs) já que a amplitude entre a carga horária mínima e máxima está compreendida entre 3.000 e 4.200 horas para a integralização do curso. Contudo o $§ 5$. do artigo 3. $\mathrm{informa}$ que a carga horária destinada ao cumprimento da Base Nacional Comum Curricular (BNCC) não poderá ser superior a 1.800 horas.

As indicações de extinção de carga horária da "base comum" pela determinação da reforma do ensino médio e da implantação da BNCC com redução da carga horária para 1.800 causa um prejuízo direto, especialmente para o institutos federais que contemplam em sua matriz curricular para o ensino médio o mínimo de 2.000 horas para a base nacional comum distribuídas em disciplinas. Nessas circunstâncias ocorre uma redução obrigatória e impositiva quanto à carga horária destinada à base comum, com prejuízo direto para as disciplinas de Filosofia, Educação Física, Artes e Sociologia, uma vez que estas, conforme veremos adiante, não mais figuram no currículo da reforma do ensino médio e no documento da nova BNCC. Sendo assim, a redução da carga horária destinada ao núcleo básico apresentada pela reforma do ensino médio altera a estrutura curricular dos cursos dos IFs em prejuízo à formação integral do estudante.

Ainda na tentativa de elucidar as consequências que o estabelecimento de uma carga horária máxima para os conteúdos básicos poderia causar na estruturação do currículo do ensino médio, podemos entender que essa nova realidade contribui de 
maneira mais intensa para uma precoce profissionalização dos estudantes. Vejamos o que diz o texto da lei, no artigo 35-A da LDB:

A Base Nacional Comum Curricular definirá direitos e objetivos de aprendizagem do ensino médio, conforme diretrizes do Conselho Nacional de Educação, nas seguintes áreas do conhecimento: I - linguagens e suas tecnologias; II - matemática e suas tecnologias; III - ciências da natureza e suas tecnologias; IV - ciências humanas e sociais aplicadas (BRASIL, 1996).

Essas áreas de conhecimento compõem quatro itinerários de formação do estudante, estabelecidos no artigo 36, não sendo contemplado apenas o itinerário de formação técnica e profissional.

Essa organização da estrutura curricular revelada na lei indica que a carga horária para os itinerários de linguagens e suas tecnologias, matemática e suas tecnologias, ciências da natureza e suas tecnologias e ciências humanas e sociais aplicadas, que estão definidas na BNCC, serão no máximo de 1800 horas. Ou seja, o restante das horas para a integralização do curso deverá ser cumprido pelo estudante com projetos envolvendo temas transversais, com a formação técnica e profissional e também com outras atividades previstas no texto da lei, tais como o reconhecimento de competências a partir de demonstração prática, experiência de trabalho supervisionado ou outra experiência adquirida fora do ambiente escolar, atividades de educação técnica oferecidas em outras instituições de ensino credenciadas, cursos oferecidos por centros ou programas ocupacionais, estudos realizados em instituições de ensino nacionais ou estrangeiras, cursos realizados por meio de educação a distância ou educação presencial mediada por tecnologias. Para complementar o conjunto de atividades que o estudante pode utilizar para a integralização da carga horária do ensino médio, o Ministério da Educação (2018) autorizou em 2018 a inclusão de horas de trabalho voluntário em históricos acadêmicos de escolas, descaracterizando de forma mais acentuada o currículo do ensino médio.

Ainda de maneira contraditória à formação integral do aluno, o § 15 do artigo 36 da LDB indica que a reforma do ensino médio possibilita que o currículo possa ser organizado em módulos e adotar o sistema de créditos com terminalidade específica, estabelecendo um retorno aos modelos do ensino técnico profissional de caráter puramente laboral e voltado para o mercado de trabalho, evidenciando uma formação descontinuada, fragmentada e operacional ao estudante. A clara referência ao 
reconhecimento de competências presente na reforma do ensino médio e também nas diretrizes pedagógicas da BNCC atrelado à possibilidade de certificação dessas em diferentes etapas do curso demonstra o sentido de qualificação para o trabalho que essa etapa do ensino básico ganha a partir desses dispositivos legais.

Ademais, podemos observar na prática a oportunidade de avançar um processo de terceirização da educação básica sem compromisso com a formação integral do estudante e com a sociedade brasileira, deixando os objetivos educacionais do país compartilhados com as instituições de ensino e empresas privadas, que apresentam objetivos e fins diferentes da escola pública. Essa dicotomia existente entre público/privado, considerando que a ideia de público contrasta imediatamente a ideia de privado, apresenta-se como uma realidade bastante evidente no texto da reforma do ensino médio. Conforme Bobbio (2017) nos informa, o interesse público determina-se imediatamente em relação e em contraste com o interesse privado e vice-versa.

Um dos lugares comuns do secular debate sobre a relação entre a esfera do público e do privado é que, aumentando a esfera do público, diminui a do privado, e aumentando a esfera do privado diminui a do público; uma constatação que é geralmente acompanhada e complicada por juízos de valor contrapostos (BOBBIO, 2017, p. 15).

Bobbio ainda cita que, no percurso de transformação das sociedades industriais mais avançadas, a existência do processo de "privatização do público" representa "a revanche dos interesses privados através dos grandes grupos que se servem dos aparatos públicos para o alcance dos próprios objetivos" (BOBBIO, 2017, p. 33). A partir desse entendimento podemos questionar qual o sentido da reforma do ensino médio quando permite que entes privados possam assumir a responsabilidade de atividades constituintes do currículo do EM, promovendo um antagonismo de finalidades entre as ações específicas da escola e o cumprimento de carga horária fora dela.

Outro elemento que evidencia a contradição da formação integral do estudante a partir da reforma do ensino médio é a garantia apenas das disciplinas de língua portuguesa, matemática e inglês obrigatoriamente no currículo escolar. 0 legislador desconsidera os conhecimentos produzidos historicamente pela sociedade em outras áreas da ciência e não garante a obrigatoriedade das disciplinas de Artes, Educação Física, Sociologia e Filosofia e afirma que elas serão incluídas no currículo por meio de "estudos e práticas" (BNCC, 2017). Esse termo ainda carece de uma orientação 
complementar mais adequada pelo legislador, já que nesses moldes não se garante um espaço oficial para essas disciplinas no currículo e cria uma problemática quanto ao exercício profissional, conforme a legislação específica (LDB), em decorrência da notória possibilidade de profissionais com diferentes habilitações desenvolverem os conteúdos inerentes a essas áreas de conhecimento.

Para finalizar, ainda evidenciando as contradições no texto da lei de reforma do ensino médio, e possibilitando uma evidente diferenciação entre os entes federados e os setores públicos e privados da educação, o § 3. do artigo 36 da LDB deixa a critério dos sistemas de ensino a intenção ou não de compor um itinerário formativo integrado, que se traduz na composição de componentes curriculares da Base Nacional Comum Curricular (BNCC) e dos cinco itinerários formativos já citados anteriormente. Nesse contexto, ainda que pese as modificações de componentes curriculares e disciplinas previstas nessa reforma, ainda será possibilitada uma formação ao estudante que compreenda todas as áreas do conhecimento já estabelecidas.

Diante da análise normativa apresentada, é importante destacar a importância de reflexões e estudos concernentes aos princípios e fins das instituições educacionais do Brasil e, especificamente, quanto à autonomia institucional no que tange à formulação e implementação de suas próprias políticas curriculares. Esse fato se torna evidente em relação aos institutos federais de educação, ciência e tecnologia, uma instituição que historicamente se destaca pelo protagonismo nas discussões e debates em torno das políticas públicas da educação básica e profissional, com destaque à oferta do ensino médio e na articulação das políticas curriculares próprias condizentes às suas finalidades e ao relevante papel social da instituição na garantia do direito à educação básica, contemplando a formação integral do jovem trabalhador em uma perspectiva emancipadora.

\section{Considerações finais}

Em síntese, neste espaço textual objetivou-se analisar o princípio de autonomia dos institutos federais, especialmente quanto à formulação/implementação da sua própria política curricular e as contradições existentes em relação aos dispostos na lei que indica a reforma do ensino médio. Diante da sua natureza autárquica, os institutos federais gozam de autonomia e da prerrogativa de decisão quanto ao planejamento pedagógico-curricular, considerando as especificidades inerentes às finalidades 
atribuídas a essa instituição. De acordo com a estrutura organizacional dos institutos federais, registra-se a autonomia na elaboração e formulação das políticas curriculares em observância ao espírito da LDB 9394/96. Ademais, a manutenção da sua estrutura pedagógico-organizacional é imprescindível para o alcance dos princípios e fins tal como previsto na legislação de criação dos institutos.

Vale pontuar os aspectos contraditórios da reforma do ensino médio em relação às especificidades da política curricular já implementada nos institutos para o ensino médio integrado: redução da carga horária prevista para os conteúdos básicos; extinção do currículo das disciplinas de Artes, Educação Física, Filosofia e Sociologia; currículo restritivo a uma formação integral; inviabilidade da promoção de uma abordagem interdisciplinar; formação fragmentada e especialização precoce. Ainda é relevante ressaltar que as modificações no texto da LDB não fazem referência à educação profissional técnica de nível médio, fato esse que também convalida a manutenção do modelo de ensino médio adotado pelos institutos federais. Ademais, a Setec, secretaria responsável pela coordenação e orientação das políticas curriculares da educação profissional, articulada ao Conselho Nacional de Educação, não participou da elaboração dessa reforma, situação que consolida a inexequibilidade das alterações observadas no ensino médio pelos institutos federais.

Portanto existem indicações jurídico-normativas que possibilitam aos institutos federais a manutenção da sua política curricular em detrimento à aceitação das modificações induzidas pela reforma do ensino médio, convalidando assim o relativo grau de autonomia e as prerrogativas dos institutos federais diante da sua atuação político-pedagógica necessária para a consolidação das suas finalidades institucionais.

\section{Referências}

BRASIL. Decreto-Lei $n^{\circ}$ 200, de 25 de fevereiro de 1967. Dispõe sobre a organização da Administração Federal. Brasília, DF, 1967.

BRASIL. Constituição Federal de 1988. Brasília, DF, 1988.

BRASIL. Leis de Diretrizes e Bases - LDB. Lei no 9.394, Brasília, DF, 1996.

BRASIL. Lei $n^{\circ}$ 11.892, de 29 de dezembro de 2008. Institui a rede federal de educação profissional e tecnológica, e cria os Institutos Federais de Educação, Ciência e Tecnologia. Congresso Nacional. Brasília, DF, 2008. 
BRASIL. Resolução CEB/CNE $\mathrm{n}^{\circ} 6$ de 20 de setembro de 2012. Define Diretrizes Curriculares Nacionais para a Educação Profissional Técnica de Nível Médio. Brasília, DF, 2012.

BRASIL. Lei $n^{\circ} .13 .415$, de 16 de fevereiro de 2017. Dispõe sobre a reforma do ensino médio brasileiro, Brasília DF, 2017.

BRASIL. Decreto no 9.005, de 14 de março de 2017. Estabelece as competências da Setec. Brasília, DF, 2017.

BRASIL. Base Nacional Comum Curricular (BNCC). Ministério da Educação (MEC). Brasília, DF, 2017.

FRIGOTTO, G. Concepções e mudanças no mundo do trabalho e o ensino médio. In: Ensino Médio Integrado: Concepção e contradições. FRIGOTTO, G. CIAVATTA, M. RAMOS, M (Orgs). São Paulo, 3ạ. Edição, Cortez editora, 2012.

FRIGOTTO, G; CIAVATTA, M; RAMOS, M. A gênese do decreto n. 5.154/2004: um debate no contexto controverso da democracia restrita. In: __. (Org.). Ensino médio integrado: concepção e contradições. São Paulo: 3ạ. Edição, Cortez editora, 2012.

BOBBIO, N. Estado, Governo, Sociedade: Fragmentos de um Dicionário Político. Editora paz e Terra, 21a. Edição, 2017.

BARROSO, J. Autonomia e Gestão das Escolas. Lisboa: Ministério da Educação. 1996.

SILVA, C J R: Institutos Federais: lei 11.892, de 29/12/2018, comentários e reflexões. Natal: IFRN, 2009.

MEIRELLES, H L. Direito Administrativo Brasileiro.42 ${ }^{\text {a }}$ ed., / atualizada até a Emenda Constitucional 90, de 15.9.2015. São Paulo: Malheiros, 2016.

MEC. Escolas e universidades poderão contar horas de trabalho voluntário. http://portal.mec.gov.br/ultimas-noticias/222-537011943/68251-escolas-euniversidades-poderao-contar-horas-de-trabalho-voluntario. Acesso em 28/08/2018. 

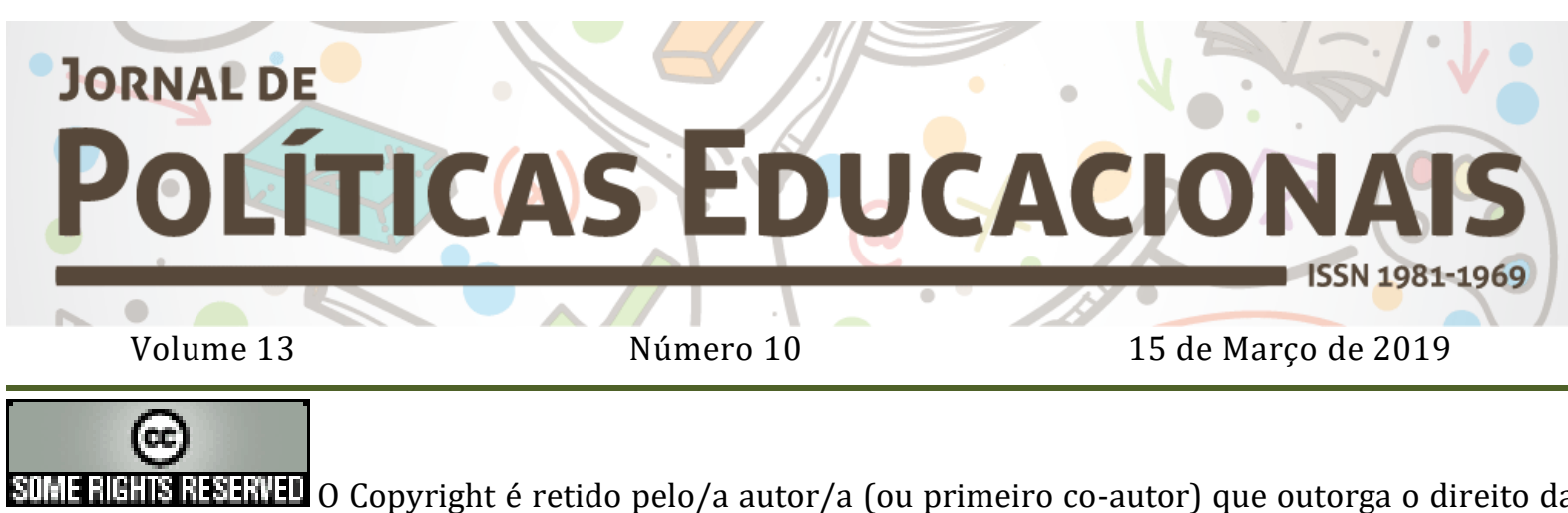

primeira publicação ao Jornal de Políticas Educacionais. Mais informação da licença de Creative Commons encontram-se em http://creativecommons.org/licenses/by-nc-nd/2.5. Qualquer outro uso deve ser aprovado em conjunto pelo/s autor/es e pelo periódico.

JoRnal de Políticas Educacionais é uma publicação do Núcleo de Políticas Educacionais do Setor de Educação da Universidade Federal do Paraná - NuPE/UFPR, em consórcio com a Linha de Pesquisa em Políticas Educacionais do Programa de Pós-Graduação em Educação - PPGE/UFPR, que aceita colaboração, reservando-se o direito de publicar ou não o material espontaneamente enviado à redação. As colaborações devem ser enviadas ao NuPE/UFPR, conforme orientações contidas nas páginas do periódico na internet: http://revistas.ufpr.br/jpe.

\author{
Indexação: \\ BBE - Biblioteca Brasileira de Educação (MEC/INEP) \\ Clase (Base de Datos Bibliográfica de Revistas de Ciencias Sociales y Humanidades) \\ Diadorim - Diretório de Política de Acesso Aberto das Revistas Científicas Brasileiras (IBICT) \\ Google Scholar \\ Index Copernicus \\ Portal de Periódicos (CAPES) \\ SER - Sistema Eletrônico de Revistas da Universidade Federal do Paraná (SER/UFPR) \\ Sumários de Revistas Brasileiras (FUNPEC-RP) \\ DRII - Directory of Research Journals Indexing
}

(Periódico integralmente disponível apenas em via eletrônica)

Jornal de Políticas Educacionais / Núcleo de Políticas Educacionais da Universidade Federal do Paraná NuPE/UFPR - v.1, n. 1 (1ํㅗ semestre de 2007) - Curitiba: NuPE/UFPR.

Volume 13, número 10 - Março de 2019.

ISSN 1981-1969

1. Educação - Periódicos. 2. Política Educacional - Periódicos. I. NuPE/UFPR

Comitê Editorial:

Elisângela Scaff (UFPR)

Daniela de Oliveira Pires (UFPR)

Ana Lorena Bruel (UFPR)

Conselho Editorial:

Andréa Barbosa Gouveia (UFPR), Ângela Hidalgo (UNICENTRO), Cesar Gernomino Tello (Universidad Nacional Tres Febrero, Argentina), Gladys Beatriz Barreyro (USP), Juca Gil (UFRGS), Jefferson Mainardes 

educacional em oposição à reforma do ensino médio.

(UEPG), João Ferreira de Oliveira (UFG), Luiz Souza Júnior (UFPB), Marcos Edgard Bassi (UFSC), Regina Maria Michelotto (UFPR), Robert Verhine (UFBA), Rosana Cruz (UFPI), Rubens Barbosa Camargo (USP), Sebastián Donoso Díaz (Universidad de Talca, Chile), Taís Moura Tavares (UFPR), Theresa Adrião (UNICAMP), Vera Peroni (UFRGS).

Créditos e Agradecimentos:

Revisão de Língua Portuguesa, Abstract e Resumen: PROGRAMA DE APOIO ÀS PUBLICAÇÕES CIENTÍFICAS PERIÓDICAS DA UFPR

Arte e diagramação: TIAGO TAVARES (iagotav@gmail.com)

Jornal de Políticas Educacionais

Universidade Federal do Paraná

Setor de Educação

Núcleo de Políticas Educacionais - NuPE/UFPR

Avenida Sete de Setembro, 2645

$2^{\circ}$ andar, Sala 213

80.230-010 - Curitiba - PR - Brasil

Tel.: 41-3535-6264

jpe@ufpr.br

http://revistas.ufpr.br/jpe 